Article

\title{
Comparative Proteomics Analyses of Pollination Response in Endangered Orchid Species Dendrobium Chrysanthum
}

\author{
Wei Wang ${ }^{1,+}\left(\mathbb{D}\right.$, Hongyang Yu ${ }^{1,2,+}$, Tinghai $\mathrm{Li}^{1}{ }^{1}$, Lexing Li ${ }^{1}$, Guoqiang Zhang ${ }^{3}$, Zhongjian Liu ${ }^{3}$, \\ Tengbo Huang ${ }^{1}$ and Yongxia Zhang ${ }^{1, *}$ \\ 1 Guangdong Provincial Key Laboratory for Plant Epigenetics, College of Life Sciences and Oceanography, \\ Shenzhen University, Shenzhen 518060, China; wangweiszuniv@163.com (W.W.); \\ hongyangyu@szu.edu.cn (H.Y.); thli90@163.com (T.L.); lilexing02@163.com (L.L.); \\ tengbohuang@szu.edu.cn (T.H.) \\ 2 Key Laboratory of Optoelectronic Devices and Systems of Ministry of Education and Guangdong Province, \\ College of Optoelectronic Engineering, Shenzhen University, Shenzhen 518060, China \\ 3 Shenzhen Key Laboratory for Orchid Conservation and Utilization, the National Orchid Conservation \\ Center of China and the Orchid Conservation \& Research Center of Shenzhen, Shenzhen 518114, China; \\ zhang2384539@163.com (G.Z.); liuzj@sinicaorchid.org (Z.L.) \\ * Correspondence: zyx@szu.edu.cn \\ + These two authors contributed equally to this work.
}

Received: 1 November 2017; Accepted: 17 November 2017; Published: 23 November 2017

\begin{abstract}
Pollination is a crucial stage in plant reproductive process. The self-compatibility (SC) and self-incompatibility (SI) mechanisms determined the plant genetic diversity and species survival. D. chrysanthum is a highly valued ornamental and traditional herbal orchid in Asia but has been declared endangered. The sexual reproduction in D. chrysanthum relies on the compatibility of pollination. To provide a better understanding of the mechanism of pollination, the differentially expressed proteins (DEP) between the self-pollination (SP) and cross-pollination (CP) pistil of D. chrysanthum were investigated using proteomic approaches-two-dimensional electrophoresis (2-DE) coupled with tandem mass spectrometry technique. A total of 54 DEP spots were identified in the two-dimensional electrophoresis (2-DE) maps between the SP and CP. Gene ontology analysis revealed an array of proteins belonging to following different functional categories: metabolic process $(8.94 \%)$, response to stimulus $(5.69 \%)$, biosynthetic process $(4.07 \%)$, protein folding $(3.25 \%)$ and transport (3.25\%). Identification of these DEPs at the early response stage of pollination will hopefully provide new insights in the mechanism of pollination response and help for the conservation of the orchid species.
\end{abstract}

Keywords: pollination response; proteomics; functional classification; Dendrobium chrysanthum

\section{Introduction}

The majority of flowering plants are hermaphroditic, that is their flowers often have male and female organs within close proximity on the same plant or even within the same flower. The mechanisms controlling floral pollination response, especially the self-/non-self-recognition, are of crucial importance for maintaining genetic variability and species survival $[1,2]$.

The self-incompatibility (SI), a genetic mechanism that is widespread among flowering plants, promotes out-crossing to increase genetic diversity within plants [3,4]. SI is found in approximately $40 \%$ of flowering plant species and in at least 100 families $[2,5,6]$. It permits the pistil to discriminate between self-pollens and cross-pollens and further to mediate the rejection of self-pollens. In flowering plants, the stigma is the receptive surface of the pistil for pollination where the integration of numerous 
events occurs during pollen recognition in SI [7-9]. The first checkpoint of SI responses is the pollen-pistil interactions. This process leads to the acceptance of compatible pollens or the rejection of self-incompatible pollens [10-13]. Then the pollen grains start to adhere, hydrate, and germinate on the stigma surface. The pollen tubes then will grow through the pistil, using a specialized mechanism of tip growth $[14,15]$.

There are two classic systems of SI: gametophytic SI (GSI) and sporophytic SI (SSI), based on modes of genetic control of pollen SI phenotype [16]. GSI is relatively widespread, and it has been found in the Solanaceae, Papaveraceae, Ranunculaceae, Leguminosae, Onagraceae, Scrophyulariaceae, Rosaceae, and Poaceae. In GSI, the haploid pollen determines the incompatibility, while in SSI it is determined by the the diploid genotype of its parent. The SSI has been found in Brassicaceae, Asteraceae, and Convolvulaceae [17].

Recent studies have made significant progresses in understanding the molecular mechanism of SI in flowering plants. In Brassica, the SI responses began with the interaction between stigma-specific $S$ receptor kinase (SRK) and the pollen coat protein S-locus Protein 11/S-locus Cysteine-Rich (SP11/SCR). The binding of SP11 induced the autophosphorylation of SRK and further triggered the downstream signaling cascades resulting in the self-pollen rejection [18-20]. In Petunia hybrida, the SI system is controlled by a single S-locus with multiple haplotypes. The S-locus consists of two genes, one is the female determinant $S$-RNases expressed in pistil, and the other is SLF/SFB (S-locus F-box/S-haplotype-specific F-box), the male determinant, expressed in pollen [21]. In Papaver papaveris, the signal molecule $S$ proteins were encoded by the $S$-locus in pistilis responsible for the SI. When pistil S proteins interact with incompatible pollen $S$ receptors, this self-incompatible interaction triggers an intracellular $\mathrm{Ca}^{2+}$ signaling cascade(s) to effect rapid inhibition of pollen growth [22].

The pollination mechanisms displayed by orchid flowers has aroused many interests among biologists over the centuries, since the first comprehensive study published by Darwin [23-25]. Research in this field is mainly focused on the relationship among orchid species and their pollinators. However, the molecular and the genetic mechanisms underlying SI are poorly understood in the orchid family. The Dendrobium, one of the largest genera within the Orchidaceae, comprises about 1200 species [26]. Most species are distributed in Australia, tropical Asia and Australasia, and many endemic species are reported along its distribution range [27-30]. This genus consists of both Self-compatibility (SC) and Self-incompatibility (SI) species [31]. Dendrobium chrysanthum is one of the SI species [32]. The sequence and phylogenetic analysis of the S-RNase and SLF-interacting SKP1-like1 (SSK1) found that none of the S-RNases in this species are the S-determinant, but do have SSK1 genes in D. chrysanthum, suggesting that a none-S-RNase based GSI in D. chrysanthum may involve diverse mechanisms which are still elusive [32]. The pollen-stigma checkpoint is the first step in the pollination process [10-13], and dissection of the pollination response at an early stage could help to understand sporophytic mechanisms in this species. Furthermore, the D. chrysanthum is a highly valued ornamental orchid which is also used in the preparation of traditional herbal medicines by Chinese and the Khasi tribe of India. Due to the excessive collection and habitat destruction, the status of this species has been declared endangered [33].

Proteomic analysis is a powerful tool that can provide systematic understanding of a biological event at the molecular level. In this study, we conducted a proteomics analysis on self-pollens or cross-pollens treated pistils derived from $D$. chrysanthum to investigate the early proteomic response between self-pollination and cross-pollination. Two-dimensional electrophoresis (2-DE) was performed to identify differentially expressed proteins, and characteristics of these proteins were examined by bioinformatic analysis. To the best of our knowledge, this is the first application of proteomic approaches to investigate the early responseof pollination in orchids and will hopefully help to identify genes involved in pollination process in D. chrysanthum. 


\section{Results and Discussion}

\subsection{Protein Profiles of D. chrysanthum in Un-Pollination, Self-Pollination and Cross-Pollination}

After extracted from pistils of un-pollination, self-pollination (SP) and cross-pollination (CP) D. chrysanthum, the total proteins were subjected to isoelectric focusing (IEF) and sodium dodecyl sulfate polyacrylamide gel electrophoresis (SDS-PAGE). After scanning, the 2-DE maps of the SP and CP pistils were obtained. To accurately and quantitatively analyze proteomic changes, spot volume differences of more than 2-fold between two identical spots were defined as significant. Three independent repeats were conducted in order to get reliable results.

Approximately, 1500 protein spots were reproducibly detected in each gel (Figures 1 and 2). In addition, these proteins were distributed evenly in the range of molecular mass 19-97 kDa and pI value 4-9. Out of the 1500 protein spots, there are 1126 common expressed protein spots in SP vs. un-pollination, 1431 in CP vs. un-pollination at $2 \mathrm{~h}$, respectively; there are 1154 common expressed protein spots in SP vs. un-pollination, 1147 in CP vs. un-pollination at $4 \mathrm{~h}$, respectively. While there were 374 differentially expressed protein spots in SP vs. un-pollination, 69 in CP vs. un-pollination at $2 \mathrm{~h}$, respectively; there were 346 differentially expressed protein spots in SP vs. un-pollination, 353 in CP vs. un-pollination at $4 \mathrm{~h}$, respectively. These differentially expressed proteins might be independently or cooperatively involved in the regulation of pollination.

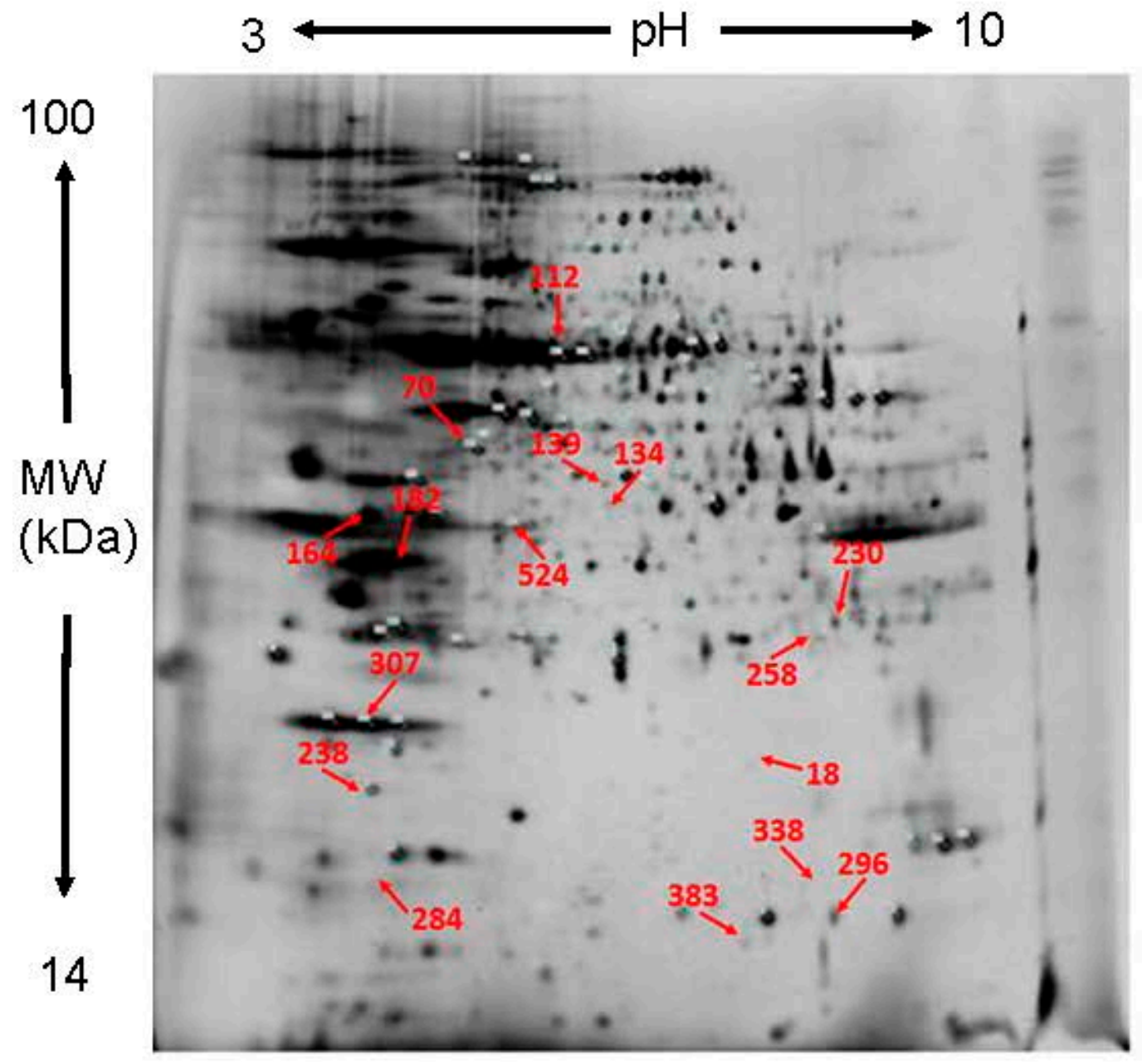

Figure 1. Two-dimensional gel electrophoresis (2-DE) of un-pollinated pistils. Red arrows demonstrate some selected protein spots, which were numbered and collected for identification by matrix-assisted laser desorption/ionization-mass spectrometry (MALDI-MS). 

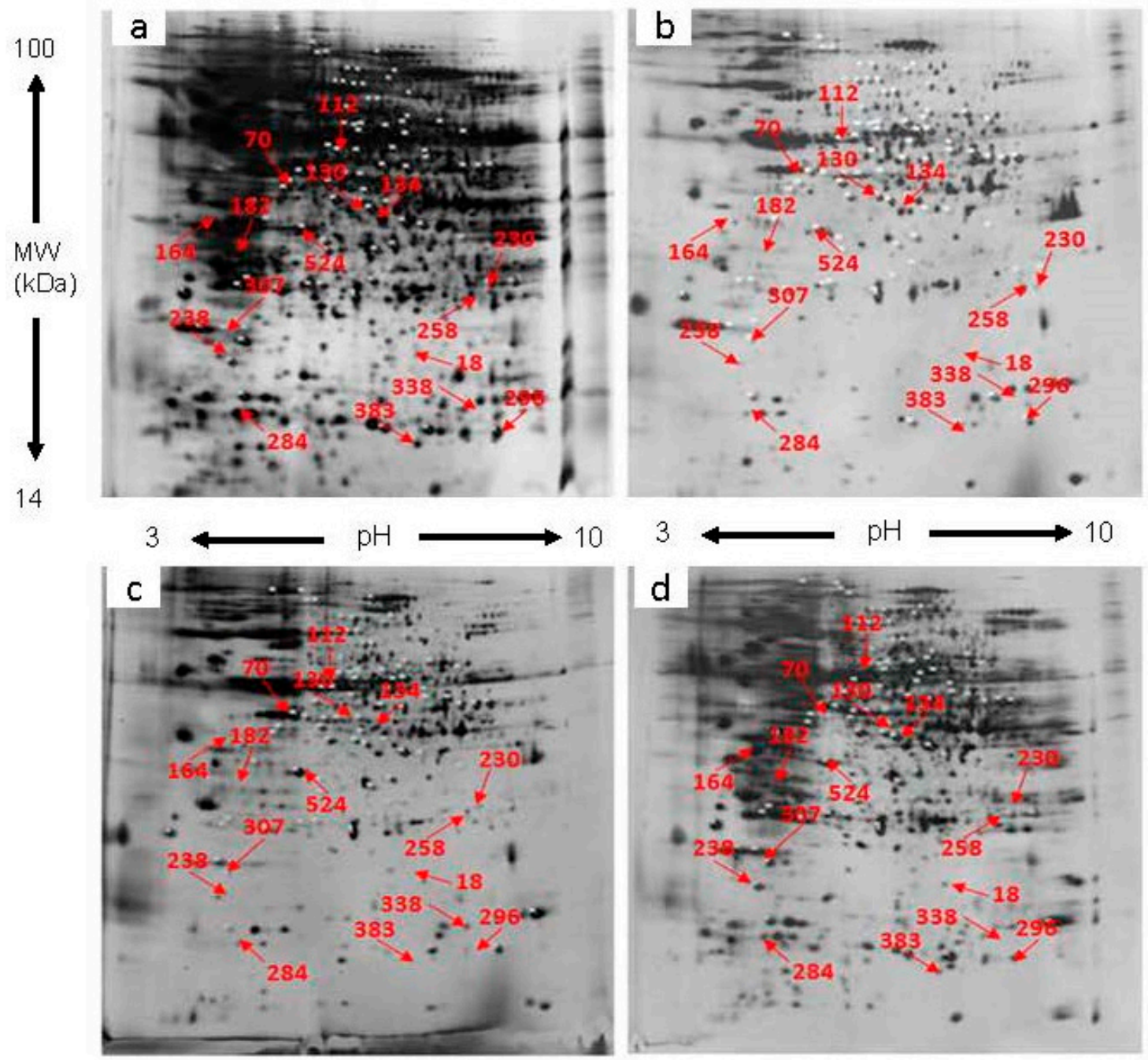

Figure 2. Representative 2-DE gel images of pistil protein profiles of $D$. chrysanthum. (a,b) 2-DE gel images of SP pistils protein profiles at $2 \mathrm{~h}$ and $4 \mathrm{~h}$ post-pollination, left and right images, respectively; (c,d) 2-DE gel images of CP pistils protein profiles at $2 \mathrm{~h}$ and $4 \mathrm{~h}$ post-pollination, left and right images, respectively. Some of the selected protein spots are demonstrated with red arrows.

\subsection{Identification of the $D E P$}

These protein spots corresponding to the differentially expressed proteins (DEPs) from the SP and the $\mathrm{CP}$ pistils were selected and excised from the 2-DE gels, and analyzed by matrix-assisted laser desorption/ionization source and tandem time-of-flight (MALDI-TOF/TOF) mass spectrometry. The mass spectrometry (MS) data was searched against NCBI protein database by using the Mascot search engine. A total of 54 proteins were successfully analyzed and identified (Table 1), including accession number, identified protein, Mascot score sequence coverage and function.

Of the 54 protein spots corresponding to DEPs, 13 were more abundant in the self-pollination 2 (SP2), and 40 were more abundant in the self-pollination 4 (SP4) (Table 1). Among the 13 DEPs in the SP2 pistil, the DEP (spot 258, accession number HS521951) and DEP (spot 284, accession number HO192248) were observed abundant. On the other hand, 23 and 27 DEPs were more abundant in the cross-pollination 2(CP2) andcross-pollination 4(CP4) samples, respectively (Table 1). Some DEPs (spot 230, accession number GE489969; and spot 238, accession number HO189451), were more abundant in the CP samples. 
Table 1. Differentially accumulated proteins identified by MS. Protein spot number refers to numbers in Figures 1 and 2. Accession number and Protein name according to the best hit of MASCOT search against NCBInr database and plant EST database. Functional protein classification according to the Uniprot database. Fold increase and decrease were calculated as SP (CP)/control and-control/SP (CP) for up and down-regulated proteins respectively. All fold changes shown are statistically significant $(p<0.05)$. PI isoelectric points, MW molecular weight, SP self-pollination, CP cross-pollination.

\begin{tabular}{|c|c|c|c|c|c|c|c|c|c|c|c|c|}
\hline \multirow{2}{*}{$\begin{array}{l}\text { Spot } \\
\text { Number }\end{array}$} & \multirow{2}{*}{ Protein Name } & \multirow{2}{*}{$\begin{array}{l}\text { Accession } \\
\text { Number }\end{array}$} & \multirow{2}{*}{$\begin{array}{l}\text { MW } \\
\text { (Da) }\end{array}$} & \multirow{2}{*}{$\begin{array}{l}\text { Protein } \\
\text { PI }\end{array}$} & \multirow{2}{*}{$\begin{array}{l}\text { Mascot } \\
\text { Score }\end{array}$} & \multirow{2}{*}{$\begin{array}{l}\text { Matched } \\
\text { Peptides }\end{array}$} & \multirow{2}{*}{$\begin{array}{c}\text { Sequence } \\
\text { Coverage }(\%)\end{array}$} & \multirow{2}{*}{ Function } & \multicolumn{4}{|c|}{ Fold Increase (+) or Decrease (-) } \\
\hline & & & & & & & & & SP 2 & SP 4 & CP 2 & CP 4 \\
\hline 18 & Dendrobiumnobile cDNA & HO192673 & 27,176 & 8.31 & 408 & 3 & 20 & fatty acid $\beta$-oxidation & $-31.2 \pm 2.23$ & $-1.8 \pm 0.14$ & $31.2 \pm 2.46$ & $20.8 \pm 1.22$ \\
\hline 31 & $\begin{array}{l}\text { Phalaenopsisequestris } \\
\text { cDNA clone EFCP035A12 }\end{array}$ & СВ033636 & 24,814 & 9.1 & 235 & 2 & 15 & $\begin{array}{l}\text { Phosphopyruvatehydratase } \\
\text { activity }\end{array}$ & $-34.4 \pm 1.80$ & $8.6 \pm 0.50$ & $15.8 \pm 0.87$ & $34.4 \pm 3.04$ \\
\hline 33 & Dendrobiumnobile cDNA & HO193941 & 27,570 & 6.03 & 194 & 2 & 12 & Transferase & $-7.6 \pm 0.59$ & $-8.4 \pm 0.47$ & $4.8 \pm 0.43$ & $8.4 \pm 0.63$ \\
\hline 62 & Dendrobiumnobile cDNA & HO189262 & 29,674 & 5.81 & 368 & 3 & 19 & $\begin{array}{l}\text { response to stress } \\
\text { mitochondrial electron }\end{array}$ & $-16.3 \pm 1.51$ & $16.3 \pm 1.15$ & $9.5 \pm 0.77$ & $-1.9 \pm 0.17$ \\
\hline 70 & $\begin{array}{l}\text { flavoprotein subunit } 2 \\
\text { [Arabidopsis thaliana] }\end{array}$ & NP_179435 & 70,015 & 5.85 & 189 & 4 & 9 & $\begin{array}{l}\text { transport, succinate to } \\
\text { ubiquinone }\end{array}$ & $-16.1 \pm 1.40$ & $10.4 \pm 0.90$ & $16.1 \pm 1.39$ & $8.7 \pm 0.61$ \\
\hline 71 & $\begin{array}{l}\text { Texas blueweed } \\
\text { Helianthus ciliaris } \\
\text { CHCL8946 }\end{array}$ & EL420682 & 31,916 & 5.93 & 80 & 1 & 5 & Zein-binding & $-19.4 \pm 1.03$ & $19.4 \pm 1.02$ & $9.2 \pm 0.60$ & $5.1 \pm 0.35$ \\
\hline 81 & $\begin{array}{l}\text { PRUPE_ppa003377mg } \\
\text { [Prunuspersica] }\end{array}$ & EMJ16224 & 62,014 & 5.8 & 179 & 2 & 5 & $\begin{array}{l}\text { metabolic process } \\
\text { magnesium ion binding }\end{array}$ & $-6.5 \pm 0.59$ & $6.5 \pm 0.33$ & $3.0 \pm 0.28$ & $-1.8 \pm 0.14$ \\
\hline 91 & $\begin{array}{c}\text { Phalaenopsisviolacea } \\
\text { cDNA }\end{array}$ & CK857713 & 29,392 & 6.99 & 114 & 1 & 6 & $\begin{array}{l}\text { ATP-binding, protein } \\
\text { folding }\end{array}$ & $-20.4 \pm 1.24$ & $18.3 \pm 1.53$ & $14.3 \pm 1.33$ & $20.4 \pm 1.17$ \\
\hline 100 & $\begin{array}{l}\text { Triticum aestivum cDNA } \\
\text { clone wl1n.pk0005.g10 }\end{array}$ & CA616775 & 17,053 & 9.3 & 82 & 1 & 9 & transmembrane transport & $-29.7 \pm 2.22$ & $13.3 \pm 1.15$ & $13.1 \pm 0.74$ & $29.7 \pm 2.44$ \\
\hline 107 & $\begin{array}{l}\text { Festuca pratensis cDNA } \\
\text { clone } 29 \mathrm{~N} 21\end{array}$ & GO893814 & 23,943 & 10.05 & 76 & 1 & 6 & uncharacterized protein & $-46.4 \pm 3.34$ & $13.6 \pm 0.76$ & $37.0 \pm 2.83$ & $46.4 \pm 2.99$ \\
\hline 112 & $\begin{array}{l}\text { 5-methyltetrahydropteroyl } \\
\text { triglutamate-homocysteine } \\
\text { [Populustrichocarpa] } \\
\text { monodehydroascorbate }\end{array}$ & XP_002319710 & 85,370 & 6.1 & 261 & 4 & 6 & $\begin{array}{c}\text { zinc ion binding, } \\
\text { methionine biosynthetic } \\
\text { process }\end{array}$ & $-91.9 \pm 6.03$ & $11.3 \pm 0.96$ & $91.9 \pm 6.36$ & $48.6 \pm 3.53$ \\
\hline 127 & $\begin{array}{l}\text { reductase [Oncidium } \\
\text { hybrid cultivar] }\end{array}$ & АCJ38541 & 46,809 & 5.26 & 205 & 4 & 17 & oxidoreductase activity & $-80.5 \pm 6.31$ & $19.3 \pm 1.48$ & $6.7 \pm 0.58$ & $-3.5 \pm 0.22$ \\
\hline 128 & Malus $x$ domestica cDNA & DT002244 & 24,691 & 8.31 & 73 & 1 & 6 & Acyltransferase & $-215.2 \pm 11.83$ & $71.8 \pm 3.97$ & $215.2 \pm 16.77$ & $5.9 \pm 0.41$ \\
\hline 134 & $\begin{array}{c}\text { VITISV_034728 [Vitis } \\
\text { vinifera] }\end{array}$ & CAN70186 & 53,150 & 6.76 & 280 & 5 & 12 & generating NADPH & $-4.5 \pm 0.29$ & $2.0 \pm 0.13$ & $4.5 \pm 0.32$ & $2.7 \pm 0.16$ \\
\hline 139 & $\begin{array}{l}\text { PRUPE_ppa003869mg } \\
\text { [Prunuspersica] }\end{array}$ & EMJ11768 & 59,411 & 6.69 & 116 & 2 & 4 & $\begin{array}{c}\text { oxidoreductase activity } \\
\text { NAD or NADP as acceptor } \\
\text { ATP-binding, }\end{array}$ & $-12.7 \pm 0.75$ & $4.2 \pm 0.28$ & $10.0 \pm 0.91$ & $12.7 \pm 1.31$ \\
\hline 151 & $\begin{array}{c}\text { Oncidium Gower Ramsey } \\
\text { cDNA }\end{array}$ & HS521850 & 30,518 & 6 & 166 & 2 & 11 & $\begin{array}{c}\text { Metal-binding, } \\
\text { succinate-CoA ligase } \\
\text { activity }\end{array}$ & $-1.1 \pm 0.10$ & $2.9 \pm 0.27$ & $2.0 \pm 0.17$ & $2.8 \pm 0.24$ \\
\hline 154 & $\begin{array}{l}\text { Soybean Seeds Containing } \\
\text { Globular-Stage Embryos } \\
\text { Glycine max cDNA }\end{array}$ & GD856994 & 3073 & 5.69 & 73 & 1 & 55 & $\begin{array}{c}\text { protein methyltransferase } \\
\text { activity }\end{array}$ & $-15.8 \pm 1.42$ & $12.8 \pm 0.94$ & $15.8 \pm 1.12$ & $14.8 \pm 1.34$ \\
\hline
\end{tabular}


Table 1. Cont

\begin{tabular}{|c|c|c|c|c|c|c|c|c|c|c|c|c|}
\hline \multirow{2}{*}{$\begin{array}{l}\text { Spot } \\
\text { Number }\end{array}$} & \multirow{2}{*}{ Protein Name } & \multirow{2}{*}{$\begin{array}{l}\text { Accession } \\
\text { Number }\end{array}$} & \multirow{2}{*}{$\begin{array}{l}\text { MW } \\
\text { (Da) }\end{array}$} & \multirow{2}{*}{$\begin{array}{l}\text { Protein } \\
\text { PI }\end{array}$} & \multirow{2}{*}{$\begin{array}{l}\text { Mascot } \\
\text { Score }\end{array}$} & \multirow{2}{*}{$\begin{array}{l}\text { Matched } \\
\text { Peptides }\end{array}$} & \multirow{2}{*}{$\begin{array}{l}\text { Sequence } \\
\text { Coverage (\%) }\end{array}$} & \multirow{2}{*}{ Function } & \multicolumn{4}{|c|}{ Fold Increase $(+)$ or Decrease $(-)$} \\
\hline & & & & & & & & & SP 2 & SP 4 & CP 2 & CP 4 \\
\hline 161 & $\begin{array}{l}\text { Phalaenopsis equestris } \\
\text { cDNA clone EFCP035E06 }\end{array}$ & CB033673 & 20,026 & 7.83 & 390 & 3 & 32 & $\begin{array}{l}\text { magnesium ion binding } \\
\text { Methionine biosynthesis }\end{array}$ & $-10.4 \pm 0.62$ & $3.0 \pm 0.18$ & $10.4 \pm 0.78$ & $2.0 \pm 0.16$ \\
\hline 162 & $\begin{array}{l}\text { DAFB seeds Malus } x \\
\text { domestica cDNA clone } \\
\text { AAWA002059 }\end{array}$ & CN887431 & 21,889 & 11.14 & 70 & 1 & 5 & $\begin{array}{l}\text { May play a role in plant } \\
\text { defense }\end{array}$ & $-15.2 \pm 0.88$ & $5.6 \pm 0.30$ & $10.3 \pm 0.81$ & $15.2 \pm 0.88$ \\
\hline 164 & $\begin{array}{l}\text { monodehydroascorbate } \\
\text { reductase [Oncidium } \\
\text { hybrid cultivar] }\end{array}$ & ACJ38541 & 46,809 & 5.26 & 206 & 4 & 17 & oxidoreductase activity & $-343.3 \pm 20.59$ & $47.3 \pm 3.42$ & $136.3 \pm 7.43$ & $343.3 \pm 25.51$ \\
\hline 165 & Dendrobiumnobile cDNA & HO189275 & 26,298 & 7.88 & 419 & 4 & 22 & $\begin{array}{l}\text { phosphoglycerate kinase } \\
\text { activity }\end{array}$ & $-13.3 \pm 0.72$ & $13.3 \pm 1.01$ & $5.2 \pm 0.39$ & $2.3 \pm 0.17$ \\
\hline 178 & $\begin{array}{c}\text { Triphysariaversicolor } \\
\text { cDNA }\end{array}$ & EY010367 & 23,141 & 10 & 77 & 1 & 6 & hydrolase activity & $-20.5 \pm 1.55$ & $2.8 \pm 0.17$ & $11.7 \pm 0.94$ & $20.5 \pm 1.38$ \\
\hline 182 & $\begin{array}{l}\text { Os02g0735200 [Oryza } \\
\text { sativa Japonica Group] }\end{array}$ & NP_001048045 & 39,405 & 5.51 & 238 & 2 & 14 & $\begin{array}{l}\text { High-affinity glutamine } \\
\text { synthetase }\end{array}$ & $-35.8 \pm 3.07$ & $35.8 \pm 2.55$ & $21.0 \pm 2.09$ & $20.6 \pm 1.62$ \\
\hline 184 & Dendrobiumnobile cDNA & HO197113 & 25,515 & 5.7 & 176 & 1 & 12 & $\begin{array}{l}\text { ATP binding, MAP kinase } \\
\text { activity }\end{array}$ & $-25.1 \pm 1.53$ & $9.9 \pm 0.84$ & $7.2 \pm 0.40$ & $25.1 \pm 2.49$ \\
\hline 187 & $\begin{array}{c}\text { Solanumhabrochaites } \\
\text { cDNA }\end{array}$ & GT169059 & 40,752 & 8.53 & 246 & 3 & 11 & $\begin{array}{l}\text { GTP-binding, protein } \\
\text { transport }\end{array}$ & $-10.1 \pm 0.82$ & $1.2 \pm 0.09$ & $5.9 \pm 0.31$ & $10.1 \pm 0.89$ \\
\hline 204 & $\begin{array}{l}\text { Dendrobiumnobile cDNA } \\
\text { Dendrobiumnobile cDNA }\end{array}$ & $\begin{array}{l}\text { HO203854 } \\
\text { HO196589 }\end{array}$ & $\begin{array}{l}30,487 \\
23,411\end{array}$ & $\begin{array}{l}8.35 \\
7.82\end{array}$ & $\begin{array}{l}221 \\
161\end{array}$ & $\begin{array}{l}2 \\
2\end{array}$ & $\begin{array}{l}13 \\
12\end{array}$ & $\begin{array}{l}\text { tricarboxylic acid cycle } \\
\text { malate metabolic process }\end{array}$ & $-1.1 \pm 0.10$ & $1.8 \pm 0.14$ & $2.2 \pm 0.16$ & $3.1 \pm 0.23$ \\
\hline 217 & Dendrobiumnobile cDNA & HO203393 & 29,572 & 9 & 234 & 3 & 16 & $\begin{array}{l}\text { malate metabolic process } \\
\text { Oxidoreductase }\end{array}$ & $-14.5 \pm 0.81$ & $14.5 \pm 0.85$ & $10.2 \pm 0.75$ & $14.0 \pm 0.83$ \\
\hline 221 & $\begin{array}{l}\text { peptide } A B C \text { transporter } \\
\text { substrate binding protein } \\
\text { [Bacilluscereus] }\end{array}$ & YP_002368400 & 63,740 & 8.69 & 662 & 5 & 13 & $\begin{array}{l}\text { Signal, ATP-driven } \\
\text { transport Metal-binding }\end{array}$ & $-2.2 \pm 0.21$ & $2.2 \pm 0.15$ & $3.9 \pm 0.29$ & $3.9 \pm 0.23$ \\
\hline 230 & $\begin{array}{c}\text { sunflower Helianthus } \\
\text { annuus cDNA clone } \\
\text { CCFS4413 }\end{array}$ & GE489969 & 30,766 & 9.36 & 86 & 1 & 5 & microtubule motor activity & $2.5 \pm 0.21$ & $10.8 \pm 0.90$ & $9.0 \pm 0.51$ & $3.8 \pm 0.24$ \\
\hline 232 & $\begin{array}{c}\text { Vanda hybrid cultivar } \\
\text { cDNA }\end{array}$ & GW392872 & 19,682 & 9.47 & 119 & 1 & 9 & $\begin{array}{l}\text { oxidoreductaseactivity, } \\
\text { zinc ion binding }\end{array}$ & $-4.6 \pm 0.26$ & $4.8 \pm 0.31$ & $3.2 \pm 0.27$ & $4.8 \pm 0.28$ \\
\hline 233 & Dendrobiumnobile cDNA & HO195954 & 27,748 & 5.56 & 112 & 1 & 7 & carboxylesterase activity & $-13.6 \pm 1.19$ & $10.0 \pm 0.93$ & $13.1 \pm 0.90$ & $2.9 \pm 0.21$ \\
\hline 238 & Dendrobiumnobile cDNA & HO189451 & 25,061 & 5.47 & 217 & 2 & 13 & $\begin{array}{l}\text { Unknown protein } \\
\text { regulation of translational }\end{array}$ & $-14.7 \pm 1.46$ & $8.4 \pm 0.51$ & $14.7 \pm 0.10$ & $13.2 \pm 0.94$ \\
\hline 240 & $\begin{array}{l}\text { Mimulusguttatus cDNA } \\
\text { clone CCIG14980 }\end{array}$ & GR000041 & 27,311 & 9.2 & 109 & 1 & 6 & $\begin{array}{l}\text { regulation of translational } \\
\text { initiation, translation } \\
\text { initiation factor activity }\end{array}$ & $2.4 \pm 0.19$ & $11.0 \pm 0.84$ & $12.2 \pm 0.77$ & $6.7 \pm 0.40$ \\
\hline 247 & $\begin{array}{c}\text { putative } \\
\text { enoyl-ACP-reductase } \\
\text { protein [Elaeisguineensis] }\end{array}$ & AEZ00840 & 38,749 & 9.27 & 229 & 3 & 18 & $\begin{array}{l}\text { Oxidoreductase, } \\
\text { enoyl-[acyl-carrier-protein] } \\
\text { reductase (NADH) activity }\end{array}$ & $2.7 \pm 1.67$ & $5.0 \pm 0.41$ & $4.5 \pm 0.35$ & $5.0 \pm 0.33$ \\
\hline 249 & $\begin{array}{l}\text { Dendrobiumnobile cDNA } \\
\text { Dendrobiumnobile cDNA }\end{array}$ & $\begin{array}{l}\text { HO192097 } \\
\text { HO190191 }\end{array}$ & $\begin{array}{l}24,344 \\
26,789\end{array}$ & $\begin{array}{l}5.22 \\
9.13\end{array}$ & $\begin{array}{l}152 \\
156\end{array}$ & $\begin{array}{l}2 \\
2\end{array}$ & $\begin{array}{l}11 \\
11\end{array}$ & $\begin{array}{l}\text { response to stress, } \\
\text { oxidoreductase activity }\end{array}$ & $4.4 \pm 0.36$ & $6.2 \pm 0.45$ & $8.2 \pm 0.64$ & $13.7 \pm 1.21$ \\
\hline 258 & $\begin{array}{c}\text { Oncidium Gower Ramsey } \\
\text { cDNA }\end{array}$ & HS521951 & 30,535 & 8.96 & 194 & 2 & 11 & Uncharacterized protein & $1.4 \pm 0.09$ & $4.0 \pm 0.20$ & $2.9 \pm 0.27$ & $6.1 \pm 0.41$ \\
\hline 261 & $\begin{array}{l}\text { Dendrobiumnobile cDNA } \\
\text { Dendrobiumnobile cDNA }\end{array}$ & $\begin{array}{l}\text { HO196032 } \\
\text { HO201509 }\end{array}$ & $\begin{array}{l}28,575 \\
27,739\end{array}$ & $\begin{array}{l}5.99 \\
8.26\end{array}$ & $\begin{array}{l}252 \\
318\end{array}$ & $\begin{array}{l}2 \\
2\end{array}$ & $\begin{array}{l}11 \\
14\end{array}$ & Uncharacterized protein & $3.1 \pm 0.25$ & $2.2 \pm 0.20$ & $4.5 \pm 0.23$ & $4.5 \pm 0.27$ \\
\hline 284 & Dendrobiumnobile cDNA & HO192248 & 23,859 & 5.75 & 99 & 1 & 6 & Uncharacterized protein & $2.3 \pm 0.21$ & $-3.1 \pm 0.30$ & $3.1 \pm 0.22$ & $5.2 \pm 0.30$ \\
\hline 294 & Panicumvirgatum cDNA & JG964858 & 30,004 & 9.4 & 84 & 1 & 5 & $\begin{array}{l}\text { transporter activity } \\
\text { biquitin-denendent }\end{array}$ & $2.0 \pm 0.17$ & $2.7 \pm 0.22$ & $4.6 \pm 0.38$ & $4.6 \pm 0.44$ \\
\hline 296 & Dendrobiumnobile cDNA & HO189346 & 23,335 & 9.36 & 271 & 2 & 18 & $\begin{array}{l}\text { protein } \\
\text { pritintaent }\end{array}$ & $3.6 \pm 0.32$ & $-9.2 \pm 0.85$ & $12.3 \pm 1.16$ & $12.3 \pm 0.91$ \\
\hline
\end{tabular}


Table 1. Cont

\begin{tabular}{|c|c|c|c|c|c|c|c|c|c|c|c|c|}
\hline \multirow{2}{*}{$\begin{array}{l}\text { Spot } \\
\text { Number }\end{array}$} & \multirow{2}{*}{ Protein Name } & \multirow{2}{*}{$\begin{array}{l}\text { Accession } \\
\text { Number }\end{array}$} & \multirow{2}{*}{$\begin{array}{l}\text { MW } \\
\text { (Da) }\end{array}$} & \multirow{2}{*}{$\begin{array}{l}\text { Protein } \\
\text { PI }\end{array}$} & \multirow{2}{*}{$\begin{array}{l}\text { Mascot } \\
\text { Score }\end{array}$} & \multirow{2}{*}{$\begin{array}{l}\text { Matched } \\
\text { Peptides }\end{array}$} & \multirow{2}{*}{$\begin{array}{c}\text { Sequence } \\
\text { Coverage (\%) }\end{array}$} & \multirow{2}{*}{ Function } & \multicolumn{4}{|c|}{ Fold Increase (+) or Decrease (-) } \\
\hline & & & & & & & & & SP 2 & SP 4 & $\mathrm{CP} 2$ & $\mathrm{CP} 4$ \\
\hline \multirow[t]{2}{*}{303} & $\begin{array}{c}\text { fibrillin-like protein } \\
\text { [Oncidium hybrid cultivar] }\end{array}$ & AAY24688 & 34,734 & 5.48 & 85 & 2 & 10 & structural molecule activity & $1.4 \pm 0.10$ & $2.2 \pm 0.14$ & $4.2 \pm 0.40$ & $4.2 \pm 0.32$ \\
\hline & $\begin{array}{c}\text { Oncidium hybrid cultivar } \\
\text { cDNA }\end{array}$ & HS524185 & 24,403 & 8.12 & 249 & 2 & 14 & & & & & \\
\hline 307 & $\begin{array}{c}\text { ascorbate peroxidase } \\
\text { [Oncidium hybrid cultivar] }\end{array}$ & АCJ38537 & 27,441 & 5.34 & 241 & 2 & 20 & $\begin{array}{l}\text { response to oxidative } \\
\text { stress }\end{array}$ & $1.2 \pm 0.11$ & $2.8 \pm 0.22$ & $4.1 \pm 0.28$ & $4.1 \pm 0.32$ \\
\hline 311 & Dendrobiumnobile cDNA & HO202862 & 29,065 & 5.26 & 655 & 4 & 26 & $\begin{array}{l}\text { triose-phosphate } \\
\text { isomerase activity }\end{array}$ & $1.3 \pm 0.12$ & $3.1 \pm 0.21$ & $3.7 \pm 0.29$ & $3.7 \pm 0.22$ \\
\hline 320 & $\begin{array}{c}\text { Oncidium Gower Ramsey } \\
\text { cDNA }\end{array}$ & HS522419 & 32,789 & 5.48 & 79 & 1 & 4 & $\begin{array}{l}\text { Zinc phosphodiesterase, } \\
\text { Endonuclease }\end{array}$ & $-1.5 \pm 0.12$ & $2.3 \pm 0.19$ & $2.2 \pm 0.20$ & $1.9 \pm 0.14$ \\
\hline 329 & $\begin{array}{l}\text { Coffeaarabica cDNA clone } \\
\text { CAET42MIX-CFEZE47TVC }\end{array}$ & GT010034 & 32,267 & 8.06 & 139 & 1 & 5 & Thaumatin-like protein & $2.1 \pm 0.18$ & $8.7 \pm 0.85$ & $3.7 \pm 0.25$ & $8.1 \pm 0.70$ \\
\hline 357 & Dendrobiumnobile cDNA & HO198288 & 24,617 & 7.72 & 217 & 3 & 15 & $\begin{array}{l}\text { PPIases accelerate the } \\
\text { folding of proteins }\end{array}$ & $-15.3 \pm 0.91$ & $10.3 \pm 0.84$ & $15.3 \pm 1.08$ & $12.4 \pm 1.09$ \\
\hline 360 & unknown [Piceasitchensis] & gi | 116779193 & 18,169 & 8.34 & 102 & 2 & 14 & $\begin{array}{l}\text { peptidyl-prolylcis-trans } \\
\text { isomerase activity }\end{array}$ & $-11.0 \pm 0.77$ & $11.0 \pm 0.83$ & $6.0 \pm 0.51$ & $-4.4 \pm 0.24$ \\
\hline 363 & $\begin{array}{l}\text { peroxiredoxin } 5 \text { cell rescue } \\
\text { protein [Loliumperenne] }\end{array}$ & AFA36612 & 11,445 & 5.13 & 160 & 2 & 31 & $\begin{array}{l}\text { oxidation-reduction } \\
\text { process }\end{array}$ & $2.0 \pm 1.48$ & $2.5 \pm 0.19$ & $6.6 \pm 0.34$ & $6.6 \pm 0.62$ \\
\hline 383 & $\begin{array}{l}\text { Ophrysfusca cDNA clone } \\
\text { Ofup2722 }\end{array}$ & HO849917 & 19,693 & 8.11 & 98 & 1 & 7 & defense response & $-9.6 \pm 0.91$ & $5.6 \pm 0.31$ & $-14.7 \pm 1.06$ & $14.7 \pm 0.79$ \\
\hline 388 & Dendrobiumnobile cDNA & HO198066 & 24,490 & 9.24 & 235 & 3 & 17 & defense response & $-17.9 \pm 1.28$ & $11.4 \pm 0.88$ & $5.6 \pm 0.54$ & $18.0 \pm 1.47$ \\
\hline 464 & $\begin{array}{c}\text { lettuce serriola Lactuca } \\
\text { serriola cDNA clone } \\
\text { QGH6B22 }\end{array}$ & BU007993 & 23,103 & 4.84 & 112 & 1 & 9 & $\begin{array}{l}\text { ATP-binding, Formation of } \\
\text { phosphoenolpyruvate }\end{array}$ & $-61.9 \pm 3.71$ & $61.9 \pm 4.49$ & $50.6 \pm 4.57$ & $-1.1 \pm 0.10$ \\
\hline 524 & $\begin{array}{l}\text { translational elongation } \\
\text { factor EF-TuM [Zea mays] }\end{array}$ & AAG32661 & 48,746 & 5.99 & 390 & 4 & 22 & $\begin{array}{l}\text { translation elongation } \\
\text { factor activity, GTP } \\
\text { catabolic process }\end{array}$ & $-3.1 \pm 0.21$ & $3.1 \pm 0.25$ & $2.9 \pm 1.74$ & $1.5 \pm 0.15$ \\
\hline 530 & $\begin{array}{l}\text { M569_05826, partial } \\
\text { [Genliseaaurea] }\end{array}$ & EPS68937 & 48,363 & 8.25 & 291 & 3 & 13 & transferase activity & $-15.0 \pm 0.94$ & $15.0 \pm 1.24$ & $15.0 \pm 1.18$ & $1.6 \pm 0.16$ \\
\hline 531 & Dendrobiumnobile cDNA & HO193012 & 26,029 & 6.5 & 299 & 2 & 16 & $\begin{array}{l}\text { zinc-containing alcohol } \\
\text { dehydrogenase family }\end{array}$ & $-4.7 \pm 0.35$ & $12.2 \pm 0.70$ & $9.8 \pm 0.60$ & $1.1 \pm 0.08$ \\
\hline
\end{tabular}




\subsection{Gene Ontology Analysis of Differentially Expressed Proteins between Self-Pollination and Cross-Pollination}

To gain functional information about these identified proteins, the Basic Local Alignment Search Tool (BLAST) was used to search for homologous proteins against the National Centre for Biotechnology Information (NCBI) non-redundant protein database. The summarized Gene Ontology (GO) mapping and annotation data of the DEPs between self-pollination and cross-pollination were shown in Figure 3. Enrichment analysis against agriGO showed that the identified proteins were associated with a wide variety of cellular processes. They were classified into the following categories according to their function, including metabolic process $(8.94 \%)$, response to stimulus $(5.69 \%)$, biosynthetic process $(4.07 \%)$, protein folding $(3.25 \%)$ and transport $(3.25 \%)$. Some proteins were involved in other biological functions, such as catalytic activity, binding, cell structure, and immune. These protein groups are likely to have critical roles in the early response of pollination. Other studies also revealed that protein biosynthesis, stress response, and metabolic process related proteins were involved in the reactions of pollen-stigma recognition in soybean [34]. Also, study on Brassica napus found that biosynthesis, signal transduction, cytoskeleton, and exocytosis related proteins were significantly changed between SI and CI, indicating that these kinds of proteins play crucial rules in the early stage of pollinationin a vary of species [35]. These differentially expressed proteins in our study will provide valuable information to investigate the mechanisms concerning the early response before the pollen tube elongation occurring in orchids. We also found that some proteins associated with immune system were significantly changed between the SP and CP samples in this study, suggesting that there is probably an orchids-specific mechanism controlling the early pollination response and possibly contribute to the later GSI,. These proteins will provide a new idea for the study of the complex regulation mechanism of self-incompatibility in orchids.

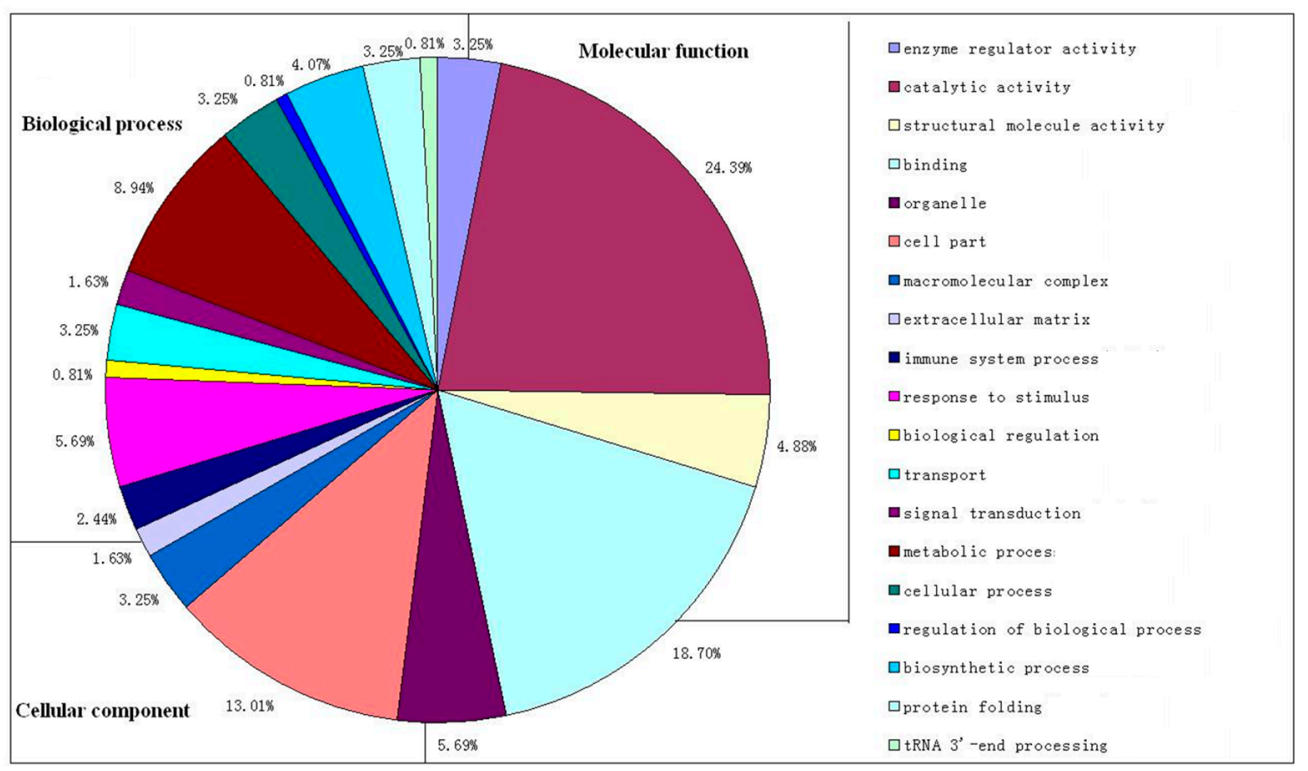

Figure 3. Functional categorization of the identified DEPs between CP and SP through gene ontology (GO) in three domains: cellular component, molecular function, and biological process according to the GO terms.

\subsection{Functional Categories of the DEGs}

To reveal common or different features between the biological characteristics of the SP and CP pistils, the functional categories of the DEPs and the proportion in each category of the SP and CP pistils were compared. The spot number profiles for the functional categories of these two sets of proteins and the relative expression levels of the proteins in each of these functional categories were 
analyzed (Figure 3). The functional categories of stigma related proteins in SP and CP pistils were found to contain the highest numbers of protein spots. Notably $9 \%$ of the DEPs were assigned to the 'metabolic process' category, especially those involved in energy metabolism pathways including glycolysis, tricarboxylic acid cycle, pentose phosphate pathway, oxidative phosphorylation, and fatty acid metabolism.

According to the presence or absence of surface exudates, stigmas are generally classified into wet and dry categories. In addition, wet stigmas secrete the liquid exudates containing proteins, liquids, carbohydrates, and water to their surface, which has been shown to be necessary for pollen-stigma interactions during pollination. Recently, specifically and preferentially expressed proteins in wet and dry stigmas of Arabidopsis (Arabidopsis thaliana), maize (Zea mays), tobacco (Nicotianatabacum) and rice (Oryza sativa) were identified [36]. We found that D. chrysanthum is a wet stigma plant species [37,38]. One protein, HO192673 (spot 18), was found to be more highly expressed in the cross-pollination pistil. This protein was predicted to function in fatty acid $\beta$-oxidation. Previous studies revealed that fatty acid $\beta$-oxidation related proteins were involved in the growing pollen tube, and also showed that these proteins could be one of the components of the wet stigma surface exudates $[36,39]$. In this study, we observed the differential expression of fatty acid $\beta$-oxidation (spot 18) at the early stage of pollination, indicating that the fatty acid $\beta$-oxidation proteins were responsible for the recognition of pollination and may be also involved in sporophytic mechanisms.

In addition, some amino acids metabolism-related enzymes, such as NP_001048045 (spot 182), XP_002319710 (spot 112) were identified to be decreased at $2 \mathrm{~h}$ in the SP pistil. These proteins are important enzymes involved in the reaction converting glutamate to glutamine, which help assimilate ammonia into glutamine for its transport in plants [40-44]. It was also reported that glutamate is the precursor for the biosynthesis of $\gamma$-aminobutyrate, which plays a critical role in regulating pollen tube growth $[45,46]$.

Furthermore, some other proteins associated with oxidative phosphorylation, such as CAN70186 (spot 134), EMJ11768 (spot 139), also had higher expression levels at $2 \mathrm{~h}$ in the cross-pollination pistil. Research showed than NADPH was thought as SI related protein [47], so these proteins may act to maintain higher respiration rate to meet the demands for ATP in SI responses [48]. In addition, this kind of DEP exhibited in the early pollination response also indicated that the differential reaction referring to respiration demands for ATP may take place when pollen-stigma interacted.

The second largest group of the differentially expressed proteins in self-pollinations and cross-pollinations belong to those involved in response stimulus. Recent studies in rice and tobacco have shown that the stress/defense and pollination response pathways were composed of similar gene sets, suggesting cross-talks between pollination and stress responses [49-53]. Some defense-related proteins were identified in our current analysis, such as HO849917 (spot 383) and HO198066 (spot 388). These proteins may respond to pollination and play key roles in the interactions between pollen grains and the stigma.

Moreover, stress may induce the accumulation of reactive oxygen species (ROS) in plants, which can cause damage to plant cells and trigger stress responses [54]. Constitutive presence of ROS is a feature of angiosperm stigma [55]. Because ROS could either be a secondary messenger or be a toxic molecule, determined by its concentration, plants initiate a ROS homeostasis system to keep ROS in an endurable concentration during pollination. In our study, protein ACJ38541 (spot 164) and ACJ38537 (spot 307), belonging to the Pyr-redox protein, were found to be increased at the cross-pollination pistil which indicated that plants invoke the glutathione-ascorbate cycle pathway to reduce excess ROS in self-pollination $[56,57]$.

In our dataset, we found the expression of some ubiquitin-related proteins was dramatically increased at the cross-pollination pistil, including HO189346 (spot 296) at $4 \mathrm{~h}$ after pollination, and NP_179435 (spot 70) at $2 \mathrm{~h}$ after pollination. Ubiquitin acts as degradation signals for proteolysis and recent studies have shown that SI responses might be activated by a phosphorylation-mediated ubiquitination mechanism after pollen grains land on pistil $[58,59]$. These data provided proteomic 
evident that the ubiquitination mechanism which are key regulators in the S-RNase based GSI [21], may also play a crucial role at the early stage of pollination response. We also identified the translational elongation factor EF-TuM (spot 524) as an up-regulated protein in cross-pollination. EF-TuM is a microtubule-associated protein and binds to the microtubule lattice [60-63], which can modulate microtubule dynamics in vitro and in vivo [64-69]. The role of EF-TuM in pollination might be related to the production and elongation of pollen tubes. However, at the early stage of pollination the pollen growth has not occurred. Therefore, the EF-TuM is likely to be involved in sporophytic mechanism, and we can infer that the stigma microtubule may also have a crucial role in the early pollination response. In addition, we found the expression of phosphopyruvate hydratase activity-related protein CB033636 (spot 31) was increased in SP4, CP2 and CP4 samples, but decreased in the SP2 sample. The phosphopyruvate hydratase was reported to be involved in the defense against fungi $[70,71]$. Previous studies have shown that a molecule associated with powdery mildew resistance, NORTIA (NTA), plays a role in the process of reception pollen tubes in synergids, suggesting that this protein is involved in both pollen tube acceptance and powdery mildew infections [72] and the decrease in SP2 may contribute to pollination response at early stage. We also found the expression of transferase activity-related protein HO193941 (spot 33) was increased in CP but decreased in SP, suggesting a positive function for the $\mathrm{CP}$ in this process. ATP is not only a major source of biochemical energy for living cells, but also acts as a signaling molecule through inter-cellular communication [73,74]. Some proteins associated with ATP-binding, such as CK857713 (spot 91), HS521850 (spot 151) and HO197113 (spot 184), were detected to be differentially expressed between SP and CP samples, suggestingthat the energy metabolism is highly related to the early pollination response.

In conclusion, our proteomic analysis revealed several important classes of proteins that were differentially expressed in self-pollination and cross-pollination. The putative functions of these proteins indicate that the enhancement of primary metabolism, expression of stress-related proteins, and biosynthesis of microtube compounds might be the key factors contributing to successful pollination. We hope these findings will further our understanding of orchid reproduction and particularly for uncovering the molecular mechanisms underlying pollination response in orchids.

\section{Materials and Methods}

\subsection{Plant Materials}

The plants of D. chrysanthum (Plant specimen number: Z.J.Liu3606) were grown under natural conditions in the Orchid Conservation \& Research Center of Shenzhen, south of China. The buds of $D$. chrysanthum were emasculated one day before flowering, and artificially pollinated on the day after flowering. Un-pollinated pistils were used as negative controls. Three groups of samples were collected from un-pollinated, self-pollinated and cross-pollinated plants, respectively. Pistil samples were collected at $2 \mathrm{~h}$ and $4 \mathrm{~h}$ after pollination. The collected samples were immediately frozen in liquid nitrogen and stored at $-80^{\circ} \mathrm{C}$ for protein extraction.

\subsection{Protein Extraction and Quantification}

Pollinated pistils (approximately $100 \mathrm{mg}$ ) frozen in liquid were ground using pestle and mortar and then suspended in $1.5 \mathrm{~mL}$ extraction solution (10\% w/v TCA in acetone, $1 \mathrm{mM}$ PMSF and $0.2 \%$ DTT) for $2 \mathrm{~h}$. The mixtures were then centrifugated for $20 \mathrm{~min}$ at $12,000 \times g$, and the pellets were washed with prechilled acetone containing $0.2 \%$ DTT. A following centrifugation at $12,000 \times g$ for $20 \mathrm{~min}$ was performed, and the pellets were dried under vacuum for $30 \mathrm{~min}$. The dried protein pellets were dissolved in lysis buffer containing $7 \mathrm{M}$ urea, $2 \mathrm{M}$ thiourea, $4 \%(w / v)$ CHAPS, $65 \mathrm{mM}$ DTT, $2 \%(v / v) \mathrm{IPG}, 10 \mathrm{mM}$ PMSF and incubated at $25{ }^{\circ} \mathrm{C}$ for $2 \mathrm{~h}$. After centrifuging at $12,000 \times \mathrm{g}$ for $20 \mathrm{~min}$, the supernatants were collected for protein quantification. Protein concentration was measured by the Bradford method with Bovine serum albumin (BSA) as a standard. Three biological replicates 
were used, and one biological replicate was a mixture of combined plant samples derived from the same treatment.

\subsection{Two-Dimensional Gel Electrophoresis}

Two-dimensional gel electrophoresis was performed according to the protocol by Shen et al. with minor modifications [75]. For the first-dimension IEF, the IPG strips were rehydrated in $250 \mu \mathrm{L}$ rehydration buffer (8 M urea, $2 \%(w / v)$ CHAPS, $0.5 \%(v / v)$ Pharmalyte $\mathrm{pH} 3-10$, and $0.002 \%$ bromophenol blue) containing $150 \mu \mathrm{g}$ protein sample. Precast $13 \mathrm{~cm}$ immobilized $\mathrm{pH}$ gradient (IPG) strips (non-linear $\mathrm{pH}=3-10$; GE Healthcare, Little Chalfont, UK) were rehydrated for $12 \mathrm{~h}$ at $30 \mathrm{~V}$. IEF conditions were performed with the following voltage program: $100 \mathrm{~V} / 2 \mathrm{~h}, 200 \mathrm{~V} / 1 \mathrm{~h}, 500 \mathrm{~V} / 1 \mathrm{~h}$, linear ramp to $1000 \mathrm{~V}$ over $1 \mathrm{~h}, 8000 \mathrm{~V}$ over $3 \mathrm{~h}$, then $8000 \mathrm{~V}$ constant for a total focusing time of $55,000 \mathrm{Vh}$. After IEF, IPG strips were incubated with $10 \mathrm{mM} \mathrm{DNPH}$ in $2 \mathrm{M} \mathrm{HCl}$ for $10 \mathrm{~min}$ at room temperature and washed with $2 \mathrm{M}$ Tris $/ 30 \%$ glycerol $(v / v)$ for $15 \mathrm{~min}$, and then incubated for $15 \mathrm{~min}$ in equilibration buffer consisting of $6 \mathrm{M}$ urea, 30\% (v/v) glycerol, 2\% (w/v) SDS, 2\% (w/v) DTT and $0.05 \mathrm{M}$ Tris- $\mathrm{HCl}, \mathrm{pH} 6.8$, and subsequently for $15 \mathrm{~min}$ in the same buffer containing $2.5 \%(w / v)$ iodoacetamide instead of DTT. The second dimensional SDS-PAGE was performed on $12 \%$ polyacrylamide gels using SE 600 Ruby system (GE healthcare). The gels were first fixed in 50\% $\mathrm{MeOH}, 12 \% \mathrm{HAc}$ and $0.05 \%$ formalin for $2 \mathrm{~h}$. The SDS-PAGE was first run at a current of $10 \mathrm{~mA} / \mathrm{gel}$ for $30 \mathrm{~min}$ and then at a constant current of $20 \mathrm{~mA} / \mathrm{gel}$ at $15{ }^{\circ} \mathrm{C}$ until bromophenol blue reached the gel bottom. Then the gels were stained in $0.2 \% \mathrm{AgNO}_{3}$ and $0.076 \%$ formalin for $20 \mathrm{~min}$. Finally, gels were developed with $6 \% \mathrm{Na}_{2} \mathrm{CO}_{3}, 0.05 \%$ formalin and $0.0004 \% \mathrm{Na}_{2} \mathrm{~S}_{2} \mathrm{O}_{3}$. Staining was stopped with $50 \% \mathrm{MeOH}$ and $12 \%$ HAc for $5 \mathrm{~min}$. 2-DEs were performed for each biological replicate individually, and the result of each treatment was the mean of three biological replicates.

\subsection{Image Acquisition and Data Analysis}

The silver-stained gels were scanned using the proXPRESS 2D imaging system (PerkinElmer, Hong Kong, China). The images were analyzed with ImageMaster 2D Platinum software version 5.0 (GE Healthcare). All 2-DE images were analyzed by the software and the identified spots were manually rechecked. The experiments were repeated two times for each sample. Only those spots that showed significantly different were considered to be differentially expressed proteins (DEPs) and characterized by mass spectrometry (MS) $(p<0.05)$. The un-pollination sample was used as control, and the DEP was the comparison between SP and CP.

\subsection{Protein Identification with MALDI-TOF/TOF MS}

For protein identification, the DEP spots of interest were excised from the 2-DE gels and destained for $30 \mathrm{~min}$. Thentryptic in-gel digestion was performed [75]. Gel chips were destained in a 1:1 solution of $30 \mathrm{mM}$ potassium ferricyanide and $100 \mathrm{mM}$ sodium thiosulfate and then equilibrated in $50 \mathrm{mM}$ ammonium bicarbonate to $\mathrm{pH}$ 8.0. After hydrating with $100 \%$ acetonitrile (ACN) and drying in a Speed Vac, the gel slices were rehydrated in a minimal volume of trypsin solution $(10 \mu \mathrm{g} / \mathrm{mL}$ trypsin, $25 \mathrm{mM} \mathrm{NH}_{4} \mathrm{HCO}_{3}$ ) and incubated at $37^{\circ} \mathrm{C}$ for $16 \mathrm{~h}$.

After trypsin digestion, the protein peptides were collected for matrix-assisted laser desorption/ionization time of flight mass spectrometry (MALDI-TOF-MS) analysis on a 5800 MALDI TOF/MS mass spectrometry (AB SIEX, Framingham, MA, USA). Protein digestion extracts (tryptic peptides) were resuspended with $5 \mu \mathrm{L}$ of $0.1 \%$ trifluoroacetic acid and then the peptide samples were mixed (1:1 ratio) with a matrix consisting of a saturated solution $\alpha$-cyano-4-hydroxy-trans-cinnamic acid in 50\% acetonitrile, $1 \%$ trifluoroacetic acid. $0.8 \mu \mathrm{L}$ liquots were spotted onto stainless steel sample target plates.

Peptide mass spectra were acquired in positive ion reflection mode, and 800-4000 m/z mass range with 1000 laser shots was used. Precursor ions were selected for MS/MS analysis according to fixed criteria (20 most intensive peaks, $\mathrm{S} / \mathrm{N}>50$ ). Energy of $1 \mathrm{kV}$ was used for collision-induced dissociation 
(CID), air was used as collision gas and 2000 acquisitions were accumulated for each MS/MS spectrum. Combined MS and MS/MS spectra were searched in the Swiss-Prot database with peptide mass fingerprinting using Mascot 2.3.02. The search was performed with the following parameters: trypsin as proteolytic enzyme with only one missed cleavage site was accepted; $100 \mathrm{ppm}$ for precursor ion tolerance and 0.3 Da for fragment ion tolerance. The identification process was repeated three times using appropriate protein spots from three different silver-stained gels. To determine the confidence of the identification proteins, three rules were applied. First, probability-based MOWSE $p<0.05$; Second, the identified proteins have to match at least 5 peptides and more than $10 \%$ protein sequences coverage; Third, when matched peptides have multiple homologous proteins, only the peptide with the highest confidence were selected.

\subsection{Statistical Analysis and Gene Ontology Analysis}

All data are presented as mean \pm SD and statistical analyses were performed by the two-tailed Student's t-test. Protein spots with fold change $>2$ and $p<0.05$ were considered as significant differentially expressed. The molecular function, cellular components and biological process of the differentially expressed proteins (DEPs) were analyzed according to the Gene Ontology (GO) database (http:/ / www.geneontology.org/). GO enrichment analysis provides all GO terms which are significantly changed in the $\mathrm{CP}$ when compared with the SP.

Acknowledgments: This study is supported by Guangdong Innovation Research Team Fund (2014ZT05S078), and the Natural Science Startup Foundation of Shenzhen University (2016101).

Author Contributions: Yongxia Zhang conceived and designed the experiments; Tinghai Li and Lexing Li performed the experiments; Wei Wang analyzed the data; Guoqiang Zhang and Zhongjian Liu contributed reagents/materials/analysis tools; Wei Wang, Hongyang Yu, Tengbo Huang and Yongxia Zhang wrote the paper.

Conflicts of Interest: The authors declare no conflict of interest.

\section{References}

1. Lord, E.M.; Russell, S.D. The mechanisms of pollination and fertilization in plants. Annu. Rev. Cell Dev. Biol. 2002, 18, 81-105. [CrossRef] [PubMed]

2. Fujii, S.; Kubo, K.; Takayama, S. Non-self- and self-recognition models in plant self-incompatibility. Nat. Plants 2016, 2, 16130. [CrossRef] [PubMed]

3. Ebert, P.R.; Anderson, M.A.; Bernatzky, R.; Altschuler, M.; Clarke, A.E. Genetic polymorphism of self-incompatibility in flowering plants. Cell 1989, 56, 255-262. [CrossRef]

4. Kalisz, S.; Vogler, D.W.; Hanley, K.M. Context-dependent autonomous self-fertilization yields reproductive assurance and mixed mating. Nature 2004, 430, 884-887. [CrossRef] [PubMed]

5. Igic, B.; Kohn, J.R. Evolutionary relationships among self-incompatibility RNases. Proc. Nat. Acad. Sci. USA 2001, 98, 13167-13171. [CrossRef] [PubMed]

6. McClure, B.A.; Gray, J.E.; Anderson, M.A.; Clarke, A.E. Self-incompatibility in Nicotianaalata involves degradation of pollen rRNA. Nature 1990, 347, 757-760. [CrossRef]

7. Goldraij, A.; Kondo, K.; Lee, C.B.; Hancock, C.N.; Sivaguru, M.; Vazquez-Santana, S.; Kim, S.; Phillips, T.E.; Cruz-Garcia, F.; McClure, B. Compartmentalization of S-RNase and HT-B degradation in self-incompatible Nicotiana. Nature 2006, 439, 805-810. [CrossRef] [PubMed]

8. Franklin-Tong, N.V.; Franklin, F.C. Gametophytic self-incompatibility inhibits pollen tube growth using different mechanisms. Trends Plant Sci. 2003, 8, 598-605. [CrossRef] [PubMed]

9. Thomas, S.G.; Franklin-Tong, V.E. Self-incompatibility triggers programmed cell death in Papaver pollen. Nature 2004, 429, 305-309. [CrossRef] [PubMed]

10. Takayama, S.; Isogai, A. Self-incompatibility in plants. Annu. Rev. Plant Biol. 2005, 56, 467-489. [CrossRef] [PubMed]

11. Chapman, L.A.; Goring, D.R. Pollen-pistil interactions regulating successful fertilization in the Brassicaceae. J. Exp. Bot. 2010, 61, 1987-1999. [CrossRef] [PubMed]

12. Kao, T.H.; Tsukamoto, T. The molecular and genetic bases of S-RNase-based self-incompatibility. Plant Cell 2004, 16, S72-S83. [CrossRef] [PubMed] 
13. McClure, B. New views of S-RNase-based self-incompatibility. Curr. Opin. Plant Biol. 2006, 9, 639-646. [CrossRef] [PubMed]

14. McClure, B.; Cruz-Garcia, F.; Romero, C. Compatibility and incompatibility in S-RNase-based systems. Ann. Bot. 2011, 108, 647-658. [CrossRef] [PubMed]

15. Franklin-Tong, V.E.; Holdaway-Clarke, T.L.; Straatman, K.R.; Kunkel, J.G.; Hepler, P.K. Involvement of extracellular calcium influx in the self-incompatibility response of Papaverrhoeas. Plant J. 2002, 29, 333-345. [CrossRef] [PubMed]

16. McClure, B.A.; Franklin-Tong, V. Gametophytic self-incompatibility: Understanding the cellular mechanisms involved in "self" pollen tube inhibition. Planta 2006, 224, 233-245. [CrossRef] [PubMed]

17. Doucet, J.; Lee, H.K.; Goring, D.R. Pollen Acceptance or Rejection: A Tale of Two Pathways. Trends Plant Sci. 2016, 21, 1058-1067. [CrossRef] [PubMed]

18. Stein, J.C.; Howlett, B.; Boyes, D.C.; Nasrallah, M.E.; Nasrallah, J.B. Molecular cloning of a putative receptor protein kinase gene encoded at the self-incompatibility locus of Brassica oleracea. Proc. Nat. Acad. Sci. USA 1991, 88, 8816-8820. [CrossRef] [PubMed]

19. Nishio, T.; Kusaba, M. Sequence diversity of SLG and SRK in Brassica oleracea L. Ann. Bot. 2000, 85, 141-146. [CrossRef]

20. Conner, J.; Tantikanjana, T.; Stein, J.C.; Kandasamy, M.K.; Nasrallah, J.B.; Nasrallah, M.E. Transgene-induced silencing of S-locus genes and related genes in Brassica. Plant J. 1997, 11, 809-823. [CrossRef]

21. Liu, W.; Fan, J.; Li, J.; Song, Y.; Li, Q.; Zhang, Y.; Xue, Y. SCF(SLF)-mediated cytosolic degradation of S-RNase is required for cross-pollen compatibility in S-RNase-based self-incompatibility in Petunia hybrida. Front. Genet. 2014, 5, 228. [CrossRef] [PubMed]

22. Bosch, M.; Franklin-Tong, V.E. Self-incompatibility in Papaver: Signalling to trigger PCD in incompatible pollen. J. Exp. Bot. 2008, 59, 481-490. [CrossRef] [PubMed]

23. Johansen, B. Incompatibility in Dendrobium (Orchidaceae). Bot. J. Linn. Soc. 1990, 103, 165-196. [CrossRef]

24. Pang, S.; Pan, K.; Wang, Y.; Li, W.; Zhang, L.; Chen, Q. Floral morphology and reproductive biology of Dendrobiumjiajiangense (Orchidaceae) in Mt. Fotang, southwestern China. Flora 2012, 207, 469-474. [CrossRef]

25. Huda, M.K.; Wilcock, C.C. Rapid flower senescence following male function and breeding systems of some tropical orchids. Plant Biol. 2012, 14, 278-284. [CrossRef] [PubMed]

26. Adams, P.B. Systematics of Dendrobiinae (Orchidaceae), with special reference to Australian taxa. Bot. J. Linn. Soc. 2011, 166, 105-126. [CrossRef]

27. Chen, W.; Cheng, X.; Zhou, Z.; Liu, J.; Wang, H. Molecular cloning and characterization of a tropinone reductase from Dendrobiumnobile Lindl. Mol. Biol. Rep. 2013, 40, 1145-1154. [CrossRef] [PubMed]

28. Feng, S.; Jiang, Y.; Wang, S.; Jiang, M.; Chen, Z.; Ying, Q.; Wang, H. Molecular Identification of Dendrobium Species (Orchidaceae) Based on the DNA Barcode ITS2 Region and Its Application for Phylogenetic Study. Int. J. Mol. Sci. 2015, 16, 21975-21988. [CrossRef] [PubMed]

29. Hajong, S.; Kumaria, S.; Tandon, P. Compatible fungi, suitable medium, and appropriate developmental stage essential for stable association of Dendrobium chrysanthum. J. Basic Microbiol. 2013, 53, 1025-1033. [CrossRef] [PubMed]

30. Vasudevan, R.; Staden, J.V. Fruit harvesting time and corresponding morphological changes of seed integuments influence in vitro seed germination of Dendrobiumnobile Lindl. Plant Growth Regul. 2010, 60, 237-246. [CrossRef]

31. Pinheiro, F.; Cafasso, D.; Cozzolino, S.; Scopece, G. Transitions between self-compatibility and self-incompatibility and the evolution of reproductive isolation in the large and diverse tropical genus Dendrobium (Orchidaceae). Ann. Bot. 2015, 116, 457-467. [CrossRef] [PubMed]

32. Niu, S.C.; Huang, J.; Zhang, Y.Q.; Li, P.X.; Zhang, G.Q.; Xu, Q.; Chen, L.J.; Wang, J.Y.; Luo, Y.B.; Liu, Z.J. Lack of S-RNase-Based Gametophytic Self-incompatibility in Orchids Suggests That This System Evolved after the Monocot-Eudicot Split. Front. Plant Sci. 2017, 8, 1106-1119. [CrossRef] [PubMed]

33. Zhu, G.H.; Ji, Z.H.; Wood, J.J.; Wood, H.P. Dendrobium; Flora of China; Scientific Press: Beijing, China, 2009; pp. 367-397.

34. Li, M.; Sha, A.; Zhou, X.; Yang, P. Comparative proteomic analyses reveal the changes of metabolic features in soybean (Glycine max) pistils upon pollination. Sex. Plant Reprod. 2012, 25, 281-291. [CrossRef] [PubMed] 
35. Samuel, M.A.; Tang, W.Q.; Jamshed, M.; Northey, J.; Patel, D.; Smith, D.; Siu, K.W.M.; Muench, D.G.; Wang, Z.Y.; Goring, D.R. Proteomic analysis of Brassica stigmatic proteins following the self-incompatibility reaction reveals a role for microtubule dynamics during pollen responses. Mol. Cell Proteom. 2011, 10, 1-13. [CrossRef] [PubMed]

36. Sang, Y.L.; Xu, M.; Ma, F.F.; Chen, H.; Xu, X.H.; Gao, X.Q.; Zhang, X.S. Comparative proteomic analysis reveals similar and distinct features of proteins in dry and wet stigmas. Proteomics 2012, 12, 1983-1998. [CrossRef] [PubMed]

37. Calder, D.M.; Slater, A.T. The Stigma of Dendrobium speciosum Sm. (Orchidaceae): A New Stigma Type Comprising Detached Cells within a Mucilaginous Matrix. Ann. Bot. 1985, 55, 297-307. [CrossRef]

38. Slater, A.T.; Calder, D.M. Fine structure of the wet, detached cell stigma of the orchid Dendrobium speciosum Sm. Sex. Plant Reprod. 1990, 3, 61-69. [CrossRef]

39. Yue, X.; Gao, X.Q.; Zhang, X.S. Circadian rhythms synchronise intracellular calcium dynamics and atp production for facilitating arabidopsis pollen tube growth. Plant Signal. Behav. 2015, 10, e1017699. [CrossRef] [PubMed]

40. Brugière, N.; Dubois, F.; Limamia, A.M.; Lelandais, M.; Roux, Y.; Sangwan, R.S.; Hirel, B. Glutamine synthetase in the phloem plays a major role in controlling proline production. Plant Cell 1999, 11, 1995-2011. [CrossRef] [PubMed]

41. Canovas, F.M.; Avila, C.; Canton, F.R.; Canas, R.A.; de la Torre, F. Ammonium assimilation and amino acid metabolism in conifers. J. Exp. Bot. 2007, 58, 2307-2318. [CrossRef] [PubMed]

42. Pereira, S.; Pissarra, J.; Sunkel, C.; Salema, R. Tissue-specific distribution of glutamine synthetase in potato tubers. Ann. Bot. 1996, 77, 429-432. [CrossRef]

43. Sakurai, N.; Hayakawa, T.; Nakamura, T.; Yamaya, T. Changes in the cellular localization of cytosolic glutamine synthetase protein in vascular bundles of rice leaves at various stages of development. Planta 1996, 200, 306-311. [CrossRef]

44. Ma, H. Plant reproduction: GABA gradient, guidance and growth. Curr. Biol. 2003, 13, R834-R836. [CrossRef] [PubMed]

45. Palanivelu, R.; Brass, L.; Edlund, A.F.; Preuss, D. Pollen tube growth and guidance is regulated by POP2, an Arabidopsis gene that controls GABA levels. Cell 2003, 114, 47-59. [CrossRef]

46. Yang, Z. GABA, a new player in the plant mating game. Dev. Cell 2003, 5, 185-186. [CrossRef]

47. Wang, L.; Wang, C.; Ge, T.T.; Wang, J.J.; Liu, T.K.; Hou, X.L.; Li, Y. Expression analysis of self-incompatibility associated genes in non-heading Chinese cabbage. Genet. Mol. Res. 2014, 13, 5025-5035. [CrossRef] [PubMed]

48. Studart-Guimaraes, C.; Gibon, Y.; Frankel, N.; Wood, C.C.; Zanor, M.I.; Fernie, A.R.; Carrari, F. Identification and characterization of the $\alpha$ and $\beta$ subunits of succinyl CoA ligase of tomato. Plant Mol. Biol. 2005, 59, 781-791. [CrossRef] [PubMed]

49. Yan, S.P.; Zhang, Q.Y.; Tang, Z.C.; Su, W.A.; Sun, W.N. Comparative proteomic analysis provides new insights into chilling stress responses in rice. Mol. Cell Proteom. 2006, 5, 484-496. [CrossRef] [PubMed]

50. Li, M.N.; Xu, W.Y.; Yang, W.Q.; Kong, Z.S.; Xue, Y.B. Genome-wide gene expression profiling reveals conserved and novel molecular functions of the stigma in rice. Plant Physiol. 2007, 144, 1797-1812. [CrossRef] [PubMed]

51. Holmes-Davis, R.; Tanaka, C.K.; Vensel, W.H.; Hurkman, W.J.; McCormick, S. Proteome mapping of mature pollen of Arabidopsis thaliana. Proteomics 2005, 5, 4864-4884. [CrossRef] [PubMed]

52. Englbrecht, C.C.; Schoof, H.; Bohm, S. Conservation, diversification and expansion of $\mathrm{C}_{2} \mathrm{H}_{2}$ zinc finger proteins in the Arabidopsis thaliana genome. BMC Genom. 2004, 5, 1-17. [CrossRef] [PubMed]

53. Jung, B.G.; Lee, K.O.; Lee, S.S.; Chi, Y.H.; Jang, H.H.; Kang, S.S.; Lee, K.; Lim, D.; Yoon, S.C.; Yun, D.J.; et al. A Chinese cabbage cDNA with high sequence identity to phospholipid hydroperoxide glutathione peroxidases encodes a novel isoform of thioredoxin-dependent peroxidase. J. Biol. Chem. 2002, 277, 12572-12578. [CrossRef] [PubMed]

54. Yang, N.; Sun, Y.; Wang, Y.; Long, C.; Li, Y.; Li, Y. Proteomic analysis of the low mutation rate of diploid male gametes induced by colchicine in Ginkgo biloba L. PLoS ONE 2013, 8, e76088. [CrossRef] [PubMed]

55. McInnis, S.M.; Desikan, R.; Hancock, J.T.; Hiscock, S.J. Production of reactive oxygen species and reactive nitrogen species by angiosperm stigmas and pollen: Potential signalling crosstalk? New Phytol. 2006, 172, 221-228. [CrossRef] [PubMed] 
56. Zafra, A.; Rodriguez-Garcia, M.I.; Alche, J.D. Cellular localization of ROS and NO in olive reproductive tissues during flower development. BMC Plant Biol. 2010, 10, 36. [CrossRef] [PubMed]

57. Shi, F.; Yamamoto, R.; Shimamura, S.; Hiraga, S.; Nakayama, N.; Nakamura, T.; Yukawa, K.; Hachinohe, M.; Matsumoto, H.; Komatsu, S. Cytosolic ascorbate peroxidase 2 (cAPX 2) is involved in the soybean response to flooding. Phytochemistry 2008, 69, 1295-1303. [CrossRef] [PubMed]

58. Vierstra, R.D. The ubiquitin-26S proteasome system at the nexus of plant biology. Nat. Rev. Mol. Cell Biol. 2009, 10, 385-397. [CrossRef] [PubMed]

59. Hua, Z.; Kao, T.H. Identification and characterization of components of a putative petunia S-locus F-box-containing E3 ligase complex involved in S-RNase-based self-incompatibility. Plant Cell 2006, 18, 2531-2553. [CrossRef] [PubMed]

60. Durso, N.A.; Cyr, R.J. A calmodulin-sensitive interaction between microtubules and a higher plant homolog of elongation factor-1a. Plant Cell 1994, 6, 893-905. [CrossRef] [PubMed]

61. Olmsted, J.B. Microtubule-associated proteins. Annu. Rev. Cell Dev. B 1986, 2, 421. [CrossRef] [PubMed]

62. Chapin, S.J.; Bulinski, J.C. Microtubule stabilization by assembly-promoting microtubule-associated proteins: A repeat performance. Cell Motil. Cytoskelet. 1992, 23, 236-243. [CrossRef] [PubMed]

63. Hirokawa, N. Microtubule organization and dynamics dependent on microtubule-associated proteins. Curr. Opin. Cell Biol. 1994, 6, 74-81. [CrossRef]

64. Drechsel, D.N.; Hyman, A.A.; Cobb, M.H.; Kirschner, M.W. Modulation of the dynamic instability of tubulin assembly by the microtubule-associated protein tau. Mol. Biol. Cell 1992, 3, 1141-1154. [CrossRef] [PubMed]

65. Pryer, N.K.; Walker, R.A.; Skeen, V.P.; Bourns, B.D.; Soboeiro, M.F. Brain microtubule-associated proteins modulate microtubule dynamic instability in vitro: Realtime observations using video microscopy. J. Cell Sci. 1992, 103, 965-976. [PubMed]

66. Gamblin, T.C.; Nachmanoff, K.; Halpain, S.; Williams, R.C., Jr. Recombinant microtubule-associated protein 2c reduces the dynamic instability of individual microtubules. Biochemistry 1996, 35, 12576-12586. [CrossRef] [PubMed]

67. Gard, D.L.; Kirschner, M.W. A microtubule-associated protein from Xenopus eggs that specifically promotes assembly at the plusend. J. Cell Biol. 1987, 105, 2203-2215. [CrossRef] [PubMed]

68. Vasquez, R.J.; Gard, D.L.; Cassimeris, L. XMAP from Xenopus eggs promotes rapid plus end assembly of microtubules and rapid microtubule polymer turnover. J. Cell Biol. 1994, 127, 985-993. [CrossRef] [PubMed]

69. Dhamodharan, R.; Wadsworth, P. Modulation of microtubule dynamic instability in vivo by brain microtubule associated proteins. J. Cell Sci. 1995, 108, 1679-1689. [PubMed]

70. Wang, Y.; Ding, Y.; Wang, S.; Chen, H.; Zhang, H.; Chen, W.; Gu, Z.; Chen, Y.Q. Extract of Syzygiumaromaticum suppress eEF1A protein expression and fungal growth. J. Appl. Microbiol. 2017, 123, 80-91. [CrossRef] [PubMed]

71. Mukherjee, A.K.; Carp, M.J.; Zuchman, R.; Ziv, T.; Horwitz, B.A.; Gepstein, S. Proteomics of the response of Arabidopsis thaliana to infection with Alternaria brassicicola. J. Proteom. 2010, 73, 709-720. [CrossRef] [PubMed]

72. Kessler, S.A.; Shimosato-Asano, H.; Keinath, N.F.; Wuest, S.E.; Ingram, G.; Panstruga, R.; Grossniklaus, U. Conserved Molecular Componentsfor Pollen Tube Reception and Fungal Invasion. Science 2010, 330, 968-971. [CrossRef] [PubMed]

73. Footitt, S.; Dietrich, D.; Fait, A.; Fernie, A.R.; Holdsworth, M.J.; Baker, A.; Theodoulou, F.L. The COMATOSE ATP-Binding Cassette Transporter IsRequired for Full Fertility in Arabidopsis. Plant Physiol. 2007, 144, 1467-1480. [CrossRef] [PubMed]

74. Popova, O.B.; Baker, M.R.; Tran, T.P.; Le, T.; Serysheva, I.I. Identification of ATP-Binding Regions in the RyR1 $\mathrm{Ca}^{2+}$ Release Channel. PLoS ONE 2012, 7, e48725. [CrossRef] [PubMed]

75. Shen, L.; Chen, C.; Yang, A.; Chen, Y.; Liu, Q.; Ni, J. Redox proteomics identification of specifically carbonylated proteins in the hippocampi of triple transgenic Alzheimer's disease mice at its earliest pathological stage. J. Proteom. 2015, 123, 101-113. [CrossRef] [PubMed]

(C) 2017 by the authors. Licensee MDPI, Basel, Switzerland. This article is an open access article distributed under the terms and conditions of the Creative Commons Attribution (CC BY) license (http:/ / creativecommons.org/licenses/by/4.0/). 